\title{
EL "MUSEO" DE MANUEL MACHADO
}

\author{
Eloy Navarro Domínguez
}

\author{
Les dieux eux-mêmes meurent, \\ Mais les vers souverains \\ Demeurent \\ Plus forts que les airains. \\ (Théophile Gautier, Emaux et Camées)
}

La incorporación sistemática a la poesía de elementos procedentes de las artes plásticas constituye, como es sabido, una de las características más significativas del modernismo, en el que se unen el culto parnasiano a la belleza plástica y la visión simbolista de la unidad de las diversas artes. Pero si bien es frecuente encontrar alusiones de esta naturaleza dispersas en la obra de la mayoría de los modernistas españoles, no lo es tanto el tratamiento específico del arte como tema, y menos aún la elaboración, con una intención unitaria, de series de poemas de tales características. Al margen de los Retratos antiguos (1902) de Antonio de Zayas, poeta parnasiano, pero ajeno, cuando no abiertamente hostil, al modernismo, y de algunos poemas de La sombra del ensueño (1910), de Enrique DíezCanedo, Manuel Machado es tal vez el poeta modernista español que manifiesta un mayor interés por las artes plásticas, según queda reflejado en "Museo," sección de Alma (1902) y Alma. Museo. Los cantares (1907), y en el libro Apolo. Teatro pictórico (1911). ${ }^{1}$

Esta utilización del arte como punto de referencia para la creación poética constituye, de hecho, el germen de toda una "manera" dentro de la trayectoria de Machado, como él mismo reconocerá, a propósito de Alma. Museo. Los cantares, en su discurso de ingreso en la Real Academia:

He aquí un título que puede ya servir de epígrafe a toda mi obra lírica: Alma (poesías del reino interior, realidades puramente espirituales). Museo (poesía de la Historia a través de las obras de arte más famosas).

\footnotetext{
${ }^{1}$ Alma. (Madrid: Imprenta de A. Marzo, 1902), Alma. Museo. Los cantares (Madrid: Pueyo, 1907) Apolo. Teatro pictórico. (Madrid: Prieto, 1911).

G. Brotherston en Manuel Machado (Madrid: Taurus 1976) 125-6 menciona algunos ejemplos en autores del modernismo hispanoamericano, como Guillermo Valencia, con un poema sobre un grabado de Durero y un soneto al retrato de Erasmo por Holbein, en Ritos (1898) y asimismo Julián del Casal, con la serie de diez sonetos sobre pinturas de Moreau "Mi mundo ideal," en Nieve (1892).

Gerardo Diego en Manuel Machado, poeta (Madrid: Editora Nacional, 1974) 123-28 considera la poesía de tema pictórico de Machado como una continuación de la del Siglo de Oro, citando a Lope, Litala y Castelví. Dos fuentes de excepcional utilidad para el estudio de esta poesía pictórica del Siglo de Oro son los tratados Arte de la pintura (1649) del pintor y poeta sevillano Francisco Pacheco y Museo pictórico (1715-1724) de Antonio Palomino.
} 
Los Cantares (poesía sentimental y aun sensual, poesía de la vida rota que culmina en El mal poema. ${ }^{2}$

Sin embargo, la fórmula que presenta Machado, "poesía de la Historia a través de las obras de arte más famosas," plantea por sí misma no pocos problemas, ya que, para empezar, las "obras de arte" a las que se refiere sólo aparecen como tales en Apolo, compuesto por veinticinco sonetos sobre cuadros y estilos pictóricos, mientras que, precisamente en "Museo," la presencia de tales obras resulta algo más que difícil de detectar, a no ser que se extienda el concepto de "obra de arte" a la literatura, aspecto éste que tendremos ocasión de tratar más adelante.

Por otro lado, la historia a la que se refiere Machado hay que entenderla básicamente como historia de la cultura, es decir, de las mentalidades, las formas de vida y, en última instancia, de los estilos estéticos. De este modo, la materia que podríamos considerar estrictamente histórica (hechos y personajes fundamentalmente) aparece representada en la poesía de Machado como uno más entre los diversos temas que puede reflejar el arte. Así, junto a poemas sobre retratos de personajes históricos, es posible encontrar en Apolo otros como "La Anunciación" sobre la obra de Fra Angelico, "La Primavera," de Botticelli, los "Desnudos de mujer" de Tiziano o los "Asuntos bíblicos" del Veronés, por citar sólo algunos ejemplos ${ }^{3}$. Y otro tanto ocurre en "Museo," donde figuran poemas como "Retablo," sobre Gonzalo de Berceo, "Don Carnaval," inspirado en el Libro de Buen Amor o "Figulinas," sobre la estética rococó del siglo XVIII francés.

Además, esta particular concepción de la historia nos revela que, a pesar de la frase de Machado ("poesía de la Historia a través de las obras de arte más famosas") no existe ni en "Museo" ni en Apolo una relación de subordinación del arte como "medio" a la historia como "tema," sino que ambos se dan juntamente como temas que se manifiestan a través del medio único de la poesía. La historia está, pues, presente en "Museo" y Apolo sólo en la medida en que incluye, entre otros aspectos de la experiencia humana, el arte, así como éste lo está a su vez debido a su naturaleza intrínsecamente histórica, por lo que más que de una "poesía de la historia a través del arte" habría que hablar, en el caso de Machado, de una poesía de la historia $y$ del arte.

Con todo, hay que señalar que ambas series de textos representan de hecho dos manifestaciones diferenciadas de esa misma poética del arte y la historia. En el caso de Apolo se trata básicamente de la fórmula del "poema sobre cuadro," que se adapta sin problemas aparentes al subtítulo de "Teatro pictórico" del libro ${ }^{4}$. En "Museo," sin embargo,

2 M. Machado, y J. M Memán. Unos versos, un alma y una época. Discursos leídos en la Real Academia Española (Madrid: Diana, 1940) 79.

${ }^{3}$ En este sentido resulta interesante comparar Apolo con los Retratos antiguos de Antonio de Zayas, donde la historia sí es el objetivo principal y los cuadros están seleccionados sólo en la medida en que retratan personajes históricos más o menos identificables.

4 Tras la publicación de Apolo, Eduardo Gómez de Baquero, en Los Lunes de El Imparcial (10-4-1911), relacionó su título con el libro de Salomon Reinach Apolo. Historia general de las artes plásticas (París, 1904). Machado sin embargo negó cualquier relación: "Mi libro se llama así porque, no siendo ninguna de las nueve Musas la deidad inspiradora de la pintura y siendo Apolo, en la mitología, el padre de todas ellas, me pareció 
la adecuación entre las resonancias plásticas del título de la sección y la naturaleza de los poemas que la componen se presenta más problemática y apunta a una visión de las relaciones entre arte y literatura mucho más compleja que la reflejada en las trasposiciones de Apolo y más cercana, además, a los planteamientos centrales de la poética parnasiana.

"Museo" es, con tres poemas, una de las siete secciones que componen Alma (1902), tercer libro de Manuel Machado después de Tristes y alegres (1894) y Etcétera (1895), ambos escritos en colaboración con Enrique Paradas. ${ }^{5}$ Con posterioridad a Alma, Machado publica Caprichos (1905), La fiesta nacional (1906) y en 1907 Alma. Museo. Los cantares, segunda edición de Alma ampliada con poemas de los libros anteriores y en la que "Museo" consta de diecinueve poemas, incluidos los tres de 1902. Entre El mal poema (1909) y Apolo (1911), Machado volverá a refundir su poesía anterior en Trofeos (1910), donde figuran, esparcidos ya por diferentes secciones del libro, diecisiete poemas del "Museo" de 1907.

La sección reaparece en el segundo tomo de las Obras Completas de 1922 editada, junto a Apolo, como libro independiente, y nuevamente en Poesías. (Opera lyrica perfecta) (1924) y Poesía. (Opera omnia lyrica) (1940), ediciones todas en las que los tres poemas de la versión de 1902 se desgajan del conjunto y vuelven a integrarse en Alma, donde reproducen el primitivo "Museo." Estas tres últimas versiones desarrollan con ligeras variantes la configuración de la de 1907, por lo que será a ésta a la que nos refiramos en el presente trabajo a la hora de establecer comparaciones con respecto a la edición de $1902 .{ }^{6}$

El "Museo" de la primera edición de Alma (1902), subtitulado "Retratos de época" y dedicado "al admirable maestro Giner de los Ríos," está compuesto, como hemos señalado, por tres poemas: "Felipe IV," dedicado a Antonio de Zayas, "Oliveretto de Fermo," dedicado al actor Ricardo Calvo, y "La corte," dedicado a Jean Moréas. ${ }^{7}$

que el título cuadraba perfectamente en la índole de mi producción. Por eso se llama Apolo. No porque lo haya copiado de Reinach." En M. Machado. Alma. Apolo. A. Carballo Picazo (ed.)(Madrid: Alcalá, 1967): 101.

5 Las otras secciones de Alma son: "El reino interior," "Secretos," "Oriente," "Estatuas de sombra," "Miniaturas" y "Nieves."

${ }^{6}$ Machado incluirá en estas versiones dos nuevos poemas, "En un rincón de la Catedral" y "Las concepciones de Murillo," poemas que no serán analizados en el presente trabajo por lo tardío de su incorporación a la sección

${ }^{7}$ Zayas y Calvo fueron buenos amigos de los dos Machado. Antonio les dedicará a ambos la primera edición de Soledades y Manuel, además del "Felipe IV" de Alma, le dedicará a Zayas el poema "Carlos V" en Apolo y su libro Ars moriendi (1921), y a Calvo, además de "Oliveretto de Fermo," el poema "Un príncipe de la Casa de Orange" en Apolo. Zayas, por su parte, publicará dos retratos de los Machado en su libro Epinicios (1912).

El propio Machado se referirá a "una tertulia en casa de Ricardo Calvo, formada por mi hermano Antonio, Calvo y Antonio de Zayas, hoy duque de Amalfi... Nuestra afición era el teatro, teatro que escribíamos asimismo para ser representado por nosotros." En R. Narbona: "Lo que eran los poetas a los veinte años. El gran poeta Manuel Machado." La Voz (9-10-1933). Sobre esta tertulia ver también J. Machado, Ultimas soledades del poeta Antonio Machado (Santiago de Chile, 1948) 63, y C. González Ruano Las palabras quedan (Madrid: Afrodisio Aguado, 1957) 344.

Juan Ramón Jiménez da cuenta asimismo de la amistad entre los Machado y Zayas en R. Gullón, Conversaciones con Juan Ramón (Madrid: Taurus, 1958) 64: "A principios de siglo escribió Zayitas unos versos 
"Felipe IV," es el único poema de "Museo" que presenta un referente pictórico identificable, aunque, al contrario de lo que ocurre en los poemas de Apolo, Machado no lo menciona. El modelo es con toda probabilidad un retrato del rey pintado por Velázquez que se conserva en el Museo del Prado ( $n^{\circ} 1182$ ) aunque como señalara ya en 1968 Ricardo Navas Ruiz, el detalle del guante procede de otro retrato de Velázquez, el del Infante Don Carlos, hermano del rey, que se encuentra asimismo en el Prado $\left(\mathrm{n}^{\circ} 1188\right){ }^{8}$

En relación con la concepción general del poema podemos ver cómo el modelo pictórico determina el estatismo del retrato poético, que se halla reforzado además por el uso del presente. La adjetivación, sin embargo, contribuye a restar plasticidad a la descripción, confiriéndole una dimensión moral que a la larga acapara el sentido de todo el poema.

\section{FELIPE IV}

Nadie más cortesano ni pulido que nuestro Rey Felipe, que Dios guarde, siempre de negro hasta los pies vestido.

Es pálida su tez como la tarde, cansado el oro de su pelo undoso, y de sus ojos, el azul, cobarde.

Sobre su augusto pecho generoso, ni joyeles perturban ni cadenas el negro terciopelo silencioso.

Y, en vez de cetro real, sostiene apenas con desmayo galán un guante de ante la blanca mano de azuladas venas.

Sólo el último verso, "la blanca mano de azuladas venas," cuyo origen comentaremos más adelante, presenta un contenido descriptivo exclusivamente plástico, aunque conviene recordar que dentro del léxico del modernismo hispánico ambos adjetivos presentan una serie de connotaciones que van más allá de su significado cromático original.

En relación con las posibles fuentes del poema, Enrique Díez-Canedo ${ }^{9}$ señalaba ya en 1913 las semejanzas entre "Felipe IV" y el "César Borgia" de los Poèmes Saturniens (1866) de Verlaine, que habría de ser traducido por Machado en 1908 con versos muy similares

que no están mal. Había traído de París muchos libros y se los prestaba a los Machado. De quien era más amigo era de Manuel."

Sobre la relación entre Zayas y Antonio Machado véase J.M. Aguirre, "Antonio Machado y Antonio de Zayas (Un texto olvidado de Antonio Machado)," Papeles de Son Armadans 224-5 (1974) 265-78.

Parece ser que Machado conoció al poeta Jean Moréas durante su estancia en París entre 1899 y 1900. Sobre esta relación ver Brotherston, 25-26 y G. Gayton, Manuel Machado y los poetas simbolistas franceses. (Valencia: Bello, 1975) 29-35.

${ }^{8}$ R. Navas Ruiz, "Felipe IV,' notas a un poema," Papeles de Son Armadans XLIX (1968) 87-94. En relación con la confusión de ambos cuadros conviene recordar que el retrato del infante se consideró como de Felipe IV hasta la publicación en 1872 del Catálogo descriptivo e histórico de los cuadros del Museo del Prado de Madrid de Pedro de Madrazo.

9 "Poesías escogidas " en Revista de libros (1913) 5-6. 
cabellos negros y el negro terciopelo

contrastan, entre el oro suntuoso de la tarde,

con la palidez bella y mate de su rostro ${ }^{10}$

G. Gayton, llama la atención sobre la coincidencia en el uso del terceto con "La mort de Philippe II" de los Poèmes Saturniens ${ }^{11}$ y relaciona el retrato con el decadentismo simbolista, señalando una cierta coincidencia del poema de Machado con "Mon âme est une Infante," en Au Jardin de l'Infante (1893) de Albert Samain, poema que describe a una infanta española en El Escorial:

Les portraits de Van Dyck aux beaux doigts longs et purs,

Pâles en velours noir sur l'or vieilli des murs,

En leurs grands airs défunts la font rêver d'empire ${ }^{12}$

El propio Machado habría de comentar -en la conferencia "Génesis de un libro" (1913)el aire decadente de su "Felipe IV", a propósito precisamente del poema de Apolo "La infanta Margarita," inspirado asimismo en un cuadro de Velázquez:

Lo que he procurado es rendir en mis versos toda la elegancia, toda la decadencia, toda la infinita amargura de la deliciosa Infanta (...) Coronas que se caen de las frentes fatigadas, ojos cansados y delicadas manos incapaces de sostener ya un cetro, de puro finas y reales. Recordad los admirables retratos del IV Felipe pintados por el monstruo. [Sigue a continuación "Felipe IV" ] 13

La decadencia es efectivamente el rasgo más sobresaliente del poema, pero en ese sentido creemos que la perspectiva desde la que aparece considerada es más estética que histórica y se encuentra, por tanto, más cerca de los simbolistas franceses que de la literatura regeneracionista del fin de siglo español, como algunos han querido ver. ${ }^{14}$

En "Oliveretto de Fermo," subtitulado "Del tiempo de los Médicis," la fuente de Machado es, como ha señalado López Estrada, el capítulo VIII del Príncipe, donde Maquiavelo se refiere efectivamente al personaje del poema, ambicioso "condottiero" que habría de morir a los veintiocho años por orden de César Borgia ${ }^{15}$. El carácter literario de la

10 P. Verlaine. Fiestas galantes. Poemas saturnianos. La buena canción. Romanzas sin palabras. Sabiduría. Amor. Parábolas y otras poesías, (Madrid: Fortanet, 1908) 76.

11 Gayton, 174.

12 Gayton, 65.

13 M. Machado. La guerra literaria. M.P. Celma Valero y F. J. Blasco Pascual (eds.). (Madrid: Narcea, 1981) 131.

14 E. Bou. "Decadencia e imperio: la poesía pictórica de Manuel Machado," en J. P. Gabriele (ed.) Divergencias y perspectivas sobre la generación del 98 y Antonio Machado (Madrid: Discurso Orígenes, 1991) 125-140.

Sobre "Felipe IV" véanse asimismo:

J. G. Brotherston, "Manuel Machado y la pintura," Boletín de la Institución Fernán González XLI, 158 (1962) $117-9$

J. de Entrambasaguas, "Poesía y pintura de Manuel Machado en tres retratos," Jano 79 (1972) 79-81.

A. del Villar. "Manuel Machado y la pintura" Bellas Artes 34 (1974) 8-10.

${ }^{15}$ López Estrada, F., Los "Primitivos" de Manuel y Antonio Machado (Madrid: Cupsa, 1977) 63-66. 
fuente condiciona la concepción general del poema, donde en lugar de una descripción física en presente, como en "Felipe IV," lo que encontramos es básicamente una apretada biografía del protagonista a base de indefinidos, biografía que Machado completa por su cuenta para presentar un perfecto retrato moral "de época," en este caso del Renacimiento italiano.

Fue valiente, fue hermoso, fue artista.

Inspiró amor, terror y respeto.

En pintarle gladiando desnudo ilustró su pincel Pintoretto.

Machiavelli nos narra su historia de asesino elegante y discreto.

César Borgia le ahorcó en Sinigaglia.

Dejó un cuadro, un puñal y un soneto.

Machado inventa, efectivamente, entre otros detalles, el cuadro del protagonista, pintado por un inexistente "Pintoretto" (probable fusión de Pinturicchio y Tintoretto) y única referencia pictórica del poema, dentro del cual funciona más como simple elemento biográfico que como modelo para su composición. G. Gayton ha señalado el parecido entre el poema y "Medaille" en Les Trophées (1893), de José María de Heredia, cuyo protagonista es otro personaje del Renacimiento italiano, Sigismondo Pandolfo Malatesta, quien presenta un perfil moral similar al del personaje de Machado. ${ }^{16}$

Seigneur de Rimini, Vicaire et Podestà.

Son profil d'épervier vit, s'accuse ou recule

A la lueur d'arain d'un fauve crépuscule,

Dans l'orbe où Matteo de' Pastis l'incrusta.

Celui-ci, le meilleur, ce Sigismond Pandolphe,

Mit à sang la Romagne et la Marche et le Golfe,

Bâtit un temple, fit l'amour et le chanta.

El poema presenta además algunos elementos en común con "Etude de mains. Lacenaire", en Emaux et Camées (1852) de Theophile Gautier. Aquí, es otro asesino el protagonista, si bien su imagen no aparece tan idealizada como la de los personajes de Machado y Heredia:

En même temps molle et féroce,

Sa forme a pour l'observateur

Je ne sais quelle grâce atroce,

La grâce du gladiateur!

Criminelle aristocratie,

Par la varlope ou le marteau

Sa pulpe n'est pas endurcie,

Car son outil fut un couteau.

Saints calus du travail honnête,

On y cherche en vain votre sceau.

${ }^{16}$ Gayton, 66 
Vrai meurtrier et faux poète,

Il fut le Manfred du ruisseau!

Si en "Felipe IV" veíamos una descripción en presente condicionada por el modelo pictórico y en "Oliveretto de Fermo" una sumaria narración en pasado determinada por la fuente histórica, en "La corte" lo que encontramos es una narración en presente, forma habitual en el soneto parnasiano por su adecuación para la representación de escenas breves. Publicado originalmente como "Villamediana (Retrato de época),"17 el poema nos presenta el momento en que el conde poeta acude a una cita con la reina Isabel de Borbón, esposa de Felipe IV.18
El conde, orgullo y gloria, las damas galantea y a los nobles zahiere -madrigal y epigrama-, cuando un paje, de lejos, por señas, le llama.
No lleva el paje escudo ni señorial librea
"Venid -le dice quedo-; seguidme... ; a donde sea!
Sólo deciros puedo que es hermosa la dama...
Mas a oscuras el sitio está donde se os llama, y aún quiere que el camino desconocido os sea."
Duda un momento el conde, y recela, no en vano, que siniestra emboscada aceche sus arrojos. . . Mas, aferrando al cinto los dorados puñales,
al paje, que sonríe, resuelto da la mano. . .
Y el pajecillo rubio pone sobre sus ojos
un pañuelo bordado con las armas reales.

A diferencia de "Oliveretto de Fermo," lo narrado es sólo un breve episodio, pero el ámbito de sugerencia creado, que abarca a la reina, al rey y, efectivamente, a toda la corte, le permite a Machado, al igual que en "Oliveretto," trazar un retrato moral tanto del protagonista como del conjunto de la época. La capacidad de sugerencia, concentrada en el último verso, es efectivamente el aspecto más destacable del poema, como han sabido ver Bousoño y Gayton, quien lo pone además como ejemplo de "soneto parnasiano de fin inesperado" a la manera de Heredia. ${ }^{19}$

Así pues, es a estos tres poemas a los que Machado aplica por primera vez el título de "Museo" y es por ello que debemos buscar en el conjunto que componen el sentido que el poeta pretende dar al término en cuestión, dejando para más adelante el nuevo significado que éste adquiere en relación con los diecinueve poemas que figuran en la versión de 1907.

Tras la descripción de los poemas podemos ver cómo sólo "Felipe IV," por su referente pictórico, parece guardar una cierta relación con el título, si bien, como hemos visto, Machado no lo presenta como tal "poema sobre cuadro." En cualquier caso, su presencia es

\footnotetext{
17 Electra 1 (1901) 132

18 Véase a este respecto Luis Rosales, Pasión y Muerte del Conde de Villamediana (Madrid: Gredos, 1969) 34. 42

19 C. Bousoño, Teoría de la expresión poética. (Madrid: Gredos, 1976) 165-75. Gayton, 66-7.
} 
fundamental en "Museo," ya que, de hecho, la impresión vagamente plástica del conjunto depende en gran medida de su articulación con los dos poemas restantes, razón por la que se halla situado inmediatamente después del título. Machado, además, se sirve del significado plástico-literario del subtítulo, "Retratos de época," para homogeneizar los tres poemas, que, al margen de su fuente de inspiración, tienen en común, efectivamente, el ser retratos literarios de personajes y épocas de la historia.

Al mismo tiempo, la disposición de los poemas contribuye a reforzar la unidad del conjunto, como se puede apreciar en la simetría trazada por las referencias al rey Felipe IV en el poema que abre la sección y en el último verso de "La corte," que la cierra. Pero además, y vinculada a ésta última, podemos percibir otra forma de articulación, en este caso lineal y discursiva, entre los tres poemas. Situada inmediatamente a continuación de "Felipe IV," la vigorosa imagen de Oliveretto de Fermo se presenta como contrafigura del rey decadente y a la vez anticipa el personaje de Villamediana, como él valiente, refinado, y poeta. En "La corte," por tanto, vendría a materializarse finalmente el conflicto planteado por las dos actitudes vitales que, como arquetipos, representan los protagonistas de los dos poemas anteriores.

Consciente de la unidad que presenta el conjunto así dispuesto, Machado cierra su "Museo" de 1902 dejando fuera otros dos poemas de Alma que por su concepción, similar a la de los anteriores, podrían haber formado parte de la sección: "Castilla," sobre el Cid, y "Flores," sobre Marco Antonio y Cleopatra, poemas que flanquean respectivamente la sección y que de hecho se incorporarán a ella en la segunda edición de 1907.

Así pues, la presencia de "Felipe IV" con su trasfondo pictórico resulta capital en la concepción general de este primer "Museo", determinando, aun indirectamente, la adecuación del título al conjunto de poemas que componen la sección.

Pero el uso del término "museo" por Machado responde, más allá de "Felipe IV," a otro tipo de consideraciones. En primer lugar debemos tener en cuenta que la visión que tiene Machado de los museos es la de la Europa de su tiempo, es decir, la del museo no sólo como colección de obras de arte, sino también como espejo de la historia, o como dijera el conde de Caylus (1692-1765), "tableau de tous les siècles." E. H. Gombrich señala que se trata de un tipo de museo diferente de la galería de obras de arte del renacimiento y el barroco: "neither a treasure house nor a shrine, but a combination of the two further functions which shaped the museum in the last two centuries, (...) the functions of the depository and the didactic display." 20

A este respecto conviene recordar que Machado debe su formación artística a sus maestros en la Institución Libre de Enseñanza, de la que fue alumno entre 1883 y 1889. Como es sabido, uno de los aspectos más significativos de la pedagogía institucionista consistía en la eliminación de los libros de texto en favor del contacto directo con las materias a enseñar, por lo que las visitas a los museos resultaban imprescindibles para las

${ }^{20}$ E. H. Gombrich, "The Museum: Past, Present, Future," Critical Inquiry (1977) 449-470. 
clases de arte. ${ }^{21}$ Sin embargo, no era sólo arte lo que los alumnos de la Institución aprendían en los museos, ya que éstos eran asimismo uno de los pocos medios de que disponían para conseguir una cierta visualización de la historia. Para M.B. Cossío, esta utilización del arte era capital en la enseñanza de la historia, por ofrecerle a los niños

aquellos elementos que pueden contribuir más a despertar una imagen del pueblo o del momento histórico en la fantasía del alumno (... ) Y como nada habla tanto ni tan directamente a la fantasía como el arte, utilízase éste, muy especialmente el monumental, como núcleo de concentración para caracterizar y fijar los distintos períodos históricos ${ }^{22}$.

El uso del arte resultaba además, según Cossío, especialmente adecuado para la concepción de la historia que pretendían transmitir los institucionistas:

Esta [la Historia], como se ve, tiene desde el comienzo carácter de la historia de la cultura. No sólo porque no se reduce a la mera historia política (que, por el contrario representa muy poco en ese grado), sino porque ante los objetos y las láminas, base principal por ahora de la enseñanza, se habla más de los pueblos que de los personajes (. . .) despertando la idea (sin decirlo) de que todo lo que hay se hace por todos y de que el verdadero sujeto de la Historia no es el héroe, sino el pueblo entero, cuyo trabajo de conjunto produce la civilización ${ }^{23}$.

La Institución parece haber dejado, efectivamente, su huella en Machado, quien además de asimilar el concepto de historia como historia de la cultura debió haber asociado desde muy temprano los museos como punto de encuentro entre la historia y el arte. A este respecto, las dedicatorias a Giner de los Ríos de "Museo" y Apolo, y dentro de éste último la del poema "El caballero de la mano al pecho" a M. B. Cossío, parecen no dejar lugar a dudas. ${ }^{24}$

Esta misma visión simultánea del arte y la historia es la que encontramos en la base de la poética parnasiana. En relación con la influencia de los parnasianos franceses en Machado ya hemos mencionado, en el comentario de los poemas, al Verlaine de los Poèmes Saturniens , a Gautier y a Heredia. El mismo término "museo," a pesar de no figurar como título en ningún libro de poemas parnasiano, engloba las dos características más significativas de dicha estética: por un lado, el culto a la forma poética según el modelo de las artes plásticas y por otro la predilección, no excluyente, por los temas inspirados en el

${ }^{21}$ Brotherston se refiere en su libro a las visitas de los escolares de la Institución a los museos, en las que Giner de los Ríos y M.B. Cossío "permanecían impasibles ante un cuadro para no perjudicar la reacción de sus alumnos: sólo cuando éstos hubieran reaccionado, informarían y detallarían situando el cuadro en una época y escuela." (125).

22 M.B. Cossío, "Sobre la enseñanza de la Historia en la Institución"en Lavisse, Monod, Hinsdale, Altamira y Cossío, La enseñanza de la Historia. (Madrid: Espasa-Calpe, 1934) 161-2.

23 Cossío, 160.

24 Cossío, por su parte, habría de responder a tal dedicatoria con un homenaje de la Institución a los Machado tras el estreno de Desdichas de la Fortuna o Julianillo Valcárcel en Febrero de 1926. En tal ocasión Manuel leyó una escena de Julianillo y la elegía de Antonio a Giner de los Ríos. Ver M. B. Cossío "Homenaje a los poetas Manuel y Antonio Machado" en De su jornada (Madrid: Aguilar, 1966) 53-5. 
pasado, especialmente en civilizaciones antiguas y exóticas. Se trata, en definitiva, de componer poemas que reproduzcan el mismo efecto de las obras de arte expuestas en un museo: perfección formal y tema "antiguo." Ello no significa necesariamente que la poesía parnasiana pretenda siempre reproducir efectos plásticos; de hecho, las trasposiciones poéticas de obras de arte, o "écfrasis," constituyen tan sólo una modalidad y, ciertamente, no la más frecuente dentro de la poesía parnasiana. ${ }^{25}$ Esta perfección formal estrictamente poética tampoco implica necesariamente una concepción estática de los poemas, ya que, de hecho, la preferencia por los motivos antiguos se manifiesta con frecuencia en el tratamiento de escenas históricas o mitológicas (como en Les Trophées de Heredia), cuya narración, generalmente en presente, introduce siempre en los poemas un cierto grado de movilidad.

Así pues, dentro de las dos líneas centrales señaladas anteriormente, la poesía parnasiana se manifiesta en un conjunto de formas que van más allá de la simple trasposición estática de obras de arte, y es por ello por lo que creemos que se pueden caracterizar como poemas parnasianos los tres del "Museo" de 1902, y no sólo "Felipe IV."

Hemos dicho anteriormente que entre los autores parnasianos más significativos ningún libro de poemas tiene como título específicamente el de "Museo." No obstante, querríamos llamar la atención sobre un texto en prosa que bien pudo haber inspirado, si no el título de la sección de Machado, sí al menos algunos rasgos de "Felipe IV." Nos referimos a Tableaux a la plume, de Théophile Gautier, maestro del parnasianismo y a la vez uno de los autores franceses del siglo XIX que mayor atención habría de prestar a España. ${ }^{26}$ La obra contiene ocho artículos sobre pintura publicados por Gautier en distintos periódicos y revistas franceses entre 1850 y 1869, incluyendo una serie titulada genéricamente "Études sur les musées" entre los que se halla "Le musée espagnol" (La Presse, 27 y 28 de agosto de 1850), donde Gautier pasa revista a la colección española del Museo del Louvre, formada entonces por cuadros de Ribera, Murillo, Zurbarán y Velázquez, pintor éste último al que el autor considera como cifra de las cualidades de la pintura del barroco español. Las reflexiones de Gautier sobre la pintura española en dicho artículo se ven ampliadas por otros dos fuera de la mencionada serie: "Les cinq nouveaux tableaux espagnols du Musée du Louvre" (Le Moniteur universel, 3 de agosto de 1858), sobre cuadros de Murillo, Herrera y Zurbarán, y "Une esquisse de Velázquez" (Le Moniteur universel, 2 de enero de 1862), sobre un boceto de "La rendición de Breda" descubierto en Madrid por las mismas fechas.

Uno de los aspectos de la pintura española del barroco que más llama la atención de Gautier en "Le musée espagnol" es el de la diversidad social de los personajes representados.

\footnotetext{
25 Un caso interesante que viene a mostrarnos que en el parnasianismo no siempre es la poesía la que sigue a las artes plásticas es el del volumen colectivo Sonnets et eaux-forts (1869) -publicado por Alphonse Lemerre, el mismo editor de Le Parnasse contemporain (1866)- donde son los sonetos los que sirven de base a las ilustraciones al aguafuerte. Ver D. Scott, "The Problem of Illustrability: the Case of Sonnets et eaux fortes" Word \& Image VI, 3 (1990) 241-258.

26 Th. Gautier Tableaux a la plume (París: Eugène Fasquelle, 1880).
} 
Así, después de referirse a los personajes de extracción social más baja, Gautier pasa revista a los miembros de la corte:

Au-dessus de cette bohême et de cette cour des miracles dont nous venons de parler, se tiennent debout les infants, les grands d'Espagne, les amirantes, les belles dames, tout le monde hautain de la cour, faisant cabrer les genets au profil busqué, étinceler les armures d'acier bruni et damasquinées d'or, agaçant du bout de leur gant de buffle le museau des grands lévriers, faisant jouer l'éventail à pailletes, arrangeant du doigt le pli d'une jupe de damas ou de brocart. ${ }^{27}$

Teniendo en cuenta la fascinación de Gautier por la pintura de Velázquez y, sobre todo, por la familiaridad con que éste parece tratar a los nobles que retrata, es muy posible que el texto esté inspirado en los modelos cortesanos del pintor de Sevilla. De hecho, los caballos encabritados, como el del retrato del Conde-Duque de Olivares, son frecuentes en la pintura de Velázquez, quien asimismo habría de retratar al Conde de Benavente en armadura de acero damasquinada en oro e igualmente a una dama con un abanico de lentejuelas, la llamada "Dama del abanico" de la colección Wallace de Londres. Tampoco el detalle del guante de ante ("gant de buffle") le pasó desapercibido a Gautier, siendo precisamente el del infante don Carlos el único guante pintado por Velázquez que aparece sostenido en la posición indicada en el texto, si bien no para azuzar a ningún lebrel. ${ }^{28}$

En "Une esquisse de Velázquez" Gautier volverá sobre la imparcialidad de los retratos de Velázquez ante el pueblo y la nobleza:

Il fait les infantes et les reines galopants sur leurs genets d'Espagne en costume de chasse ou de gala, aussi bien que les philosophes, les nains et les ivrognes. La tête noble et délicate dont la pâleur se colore à peine du sang d'azur (sangre azul) [sic] des vieilles dynasties ne lui offre pas plus de difficulté que la trogne hâlée et vineuse du soudard. ${ }^{29}$

En esta palidez que deja entrever la sangre azul (la de las venas de los reales modelos) verá Gautier un motivo central de los retratos cortesanos de Velázquez:

Quel historien fait voir la décadence de la monarchie autrichienne en Espagne d'une façon plus claire et plus frappante que cette suite de portraits où le type énergique de Charles-Quint, affaibli par la transmissión, s'enerve, s'abâtardit et s'éteint dans des têtes d'une pâleur blafarde, ennuyée et maussade, dont les dernières ne sont plus que des spectres à lèvre rouge et tombante? $?^{30}$

Así pues, tras el guante de ante y la sangre azul transparentada por la piel, Gautier se detiene en la "palidez cansada" de las cabezas de la familia real (la más retratada por Velázquez fue precisamente la de Felipe IV) como símbolo de la decadencia de la dinastía de

27 Th. Gautier, Tableaux a la plume, 103.

28 Ciertamente resulta difícil no fijarse en el detalle del guante en el retrato del infante, ya que la mano desnuda que lo sostiene concentra sobre sí la escasa luz que Velázquez pone en el cuadro, estando la otra mano enguantada y el rostro del personaje semioscurecido.

${ }^{29} \mathrm{Th}$. Gautier, Tableaux a la plume, 225.

${ }^{30}$ Th. Gautier, Tableaux a la plume, 226. 
Austria. La misma imagen volverá a aparecer en otro texto de Gautier, la Guide de l'amateur au Musée du Louvre, referido esta vez específicamente a Felipe IV:

Vélasquez eut bien des fois cette tâche ingrate de peindre son roi, qui n'etait pas beau; mais les peintres espagnols, réalistes de tempérament, ne craignent pas la laideur, quoiqu'ils sachent atteindre la beauté lorsque cela est nécessaire. Aussi Vélasquez reproduisit-il, avec une résignation parfaite, cette tête molle et empâtée où se trahit l'épuisement des races. ${ }^{31}$

Ignoramos si Machado pudo haber leído estos Tableaux a la plume antes de componer su "Felipe IV," aunque sí sabemos que en la conferencia "Génesis de un libro" (1913), el poeta se sirvió de la fórmula de Gautier para definir los poemas de Apolo como "pinturas a pluma"32. En cualquier caso hay que señalar que las circunstancias en las que Machado escribe "Felipe IV" son sin duda las más favorables para la lectura de los textos de Gautier sobre pintura española, y en especial sobre Velázquez. Efectivamente, la mayor parte de los poemas de Alma fueron escritos en París entre 1899 y 1900, lejos, por tanto, de los cuadros del Museo del Prado (circunstancia que Ricardo Navas Ruiz relaciona con la confusión entre los dos retratos de Velázquez) y seguramente con los libros de Verlaine, Samain y Gautier, entre otros, bien a mano. ${ }^{33}$ Gillian Gayton se refiere además a la coincidencia de la estancia de Machado en París con un cierto "reavivamiento del interés por España"34. La Revue Hispanique aparece en 1894, el Bulletin Hispanique en 1897 y desde 1900 el Mercure de France comienza a publicar trimestralmente sus "Lettres espagnoles." Laurent Tailhade, amigo de Machado, toma el relevo de la hispanofilia de Verlaine, mientras Verhaeren, autor más tarde del drama Felipe II (1901) recorre España acompañado de Darío de Regoyos, quien ilustrará su libro L'Espagne noire (1899). Al mismo tiempo vuelven a ponerse de moda obras románticas como Hernani y Gil Blas, de Hugo, o Carmen, de Merimée, y con ellos los textos del propio Gautier inspirados en España, Tras los montes -después Voyage en Espagne- (1843) y España (1845), en los que el autor pone de manifiesto su profundo conocimiento de la pintura española. ${ }^{35}$ Por otro lado, coincidiendo con la estancia de

31 Th. Gautier. Guide de l'amateur au Musée du Louvre. Suivi de la vie et les auvres de quelques peintres. (París: Fasquelle, s.a.)113. Velázquez es uno de los cinco pintores biografiados en el libro por Gautier, quien, además, se queja de que el retrato de la infanta Margarita no se encuentre en el "Salon Carré" del Louvre, concebido como colección de obras maestras de todos los tiempos.

32 M. Machado. La guerra literaria, 120.

33 Sobre la composición de Alma entre 1899 y 1900 Machado recordaría más adelante: "Finalmente, en un hotel de la rue Vaugirard escribí mi primer libro de versos, Alma, que se publicó en Madrid en 1901 y que contenía en embrión toda mi obra poética" En R. Narbona: "Lo que eran los poetas a los veinte años. El gran poeta Manuel Machado." Entrevista. La Voz (9-10-1933).

34 G. Gayton, 40

35 Además de las innumerables referencias de Voyage en Espagne, se pueden encontrar en España los siguientes poemas: "Sainte Casilde," sobre un cuadro de la catedral de Burgos, "Sur le Promethée du Musée de Madrid," inspirado en el cuadro de Ribera, "Ribeira," (sic) sobre el mismo pintor, "Deux tableaux de Valdes Leal," sobre los dos cuadros del Hospital de la Caridad de Sevilla, y finalmente "A Zurbarán," sobre los cuadros de monjes del pintor extremeño. A la imaginería religiosa dedica Gautier los poemas "A Madrid," sobre una cabeza tallada por Martínez Montañés, "Saint Christophe d'Ecija," y "La Vierge de Tolede," y a la arquitectura "L'Escurial." En Emaux et Camées (1852), además del poema "Carmen" y de menciones a la Alhambra y el 
Machado en París, se celebra, en 1899, el tricentenario de Velázquez, que ya había anticipado Aureliano de Beruete un año antes con su Velázquez, publicado precisamente en París y en francés en su primera edición y que habría de quedar sin traducción española hasta 1987. ${ }^{36}$

En cualquier caso, y aunque nos sea imposible documentar la lectura de los Tableaux a la plume por Machado, creemos que hay al menos dos hechos que resultan incuestionables. El primero es que "Felipe IV", escrito en París, está claramente inspirado en modelos franceses, ya sean Verlaine, Samain, Gautier, o todos ellos. En este sentido creemos que es a Machado a quien, en parte, va dirigido el siguiente párrafo de Antonio de Zayas, amigo íntimo, como hemos visto, del poeta (a él va dedicado precisamente "Felipe IV"), aunque crítico acérrimo del modernismo desde su parnasianismo tradicionalista:

Obsérvase también en la novísima pléyade [los modernistas] cierta propensión a tratar los asuntos poéticos sugeridos por la historia y por las costumbres de nuestra patria, a través de los prejuicios que acerca de éstas y de aquélla han divulgado en superficiales libros los escritores de más allá del Pirineo. Parece como si los poetas se hubieran complacido en documentarse en archivos extranjeros para pintar cuadros españoles, afectando al ejecutar su labor un cansancio y un escepticismo a todas luces exóticos. 37

En segundo lugar podemos ver cómo, en su temprana atención por España (su primer viaje data de 1840), Gautier se anticipa en casi cincuenta años a Machado, e incluso a Samain, en la interpretación decadentista de los retratos cortesanos de Velázquez, y en especial de los de Felipe IV. ${ }^{38}$

Generalife, encontramos una referencia a Murillo en el poema "Le chateau du souvenir" y otra a Goya en "Inés de las Sierras."

36 A. de Beruete, Velázquez. (París: H. Laurens, 1898). La traducción española (Madrid: Cepsa, 1987) está basada en la inglesa (Londres: Methuen, 1906).

37 Antonio de Zayas. Ensayos de crítica histórica y literaria (Madrid, 1907) 41.

Como curiosidad incluimos la versión del retrato de Velázquez que da el propio Zayas en Retratos antiguos (1902), y en la que podemos ver cómo a pesar de los evidentes préstamos del poema de Machado, publicado un año antes, la descripción del personaje se halla muy lejos de cualquier interpretación decadentista:

Claros los ojos, pálida la frente,

el oro del cabello desteñido,

claro el rubio bigote retorcido

grueso el labio, la barba prominente

Correr Felipe por las venas siente

la noble sangre azul de su apellido,

de terciopelo negro revestido

y al cuello el timbre borgoñón pendiente.

Oculta el traje que severo luce

de amor y gloria el devorante fuego

que de sus noches el placer inquieta;

y a través de su risa se trasluce

que el Rey sofoca y tapa el palaciego

sus ensueños de amante y de poeta.

38 Otra interpretación en el mismo sentido, aunque en éste caso contemporánea de Machado, es la del citado Salomón Reinach en Apolo. Historia general de las artes plásticas (Madrid: Gutenberg, 1924 [4ª ed.]) 276:

"Velázquez no sólo ha pintado individuos, sino que pintó a toda una sociedad, a toda una época. En sus lienzos 
En el caso de que Machado hubiera leído efectivamente los textos de Gautier sobre Velázquez -todos ellos incluídos, como hemos visto, en estudios sobre museos-, cabría pensar en la posibilidad de que junto con la imagen decadente de Felipe IV, hubiera cristalizado en el poeta sevillano la idea del "museo" como concepto clave de la poética parnasiana. A fin de cuentas, las observaciones de Gautier sobre la técnica de Velázquez y el universo social e histórico que reflejan sus obras responden, en la misma medida que "Felipe IV," a una doble perspectiva, artística e histórica, explicable tan sólo desde la concepción moderna del museo a la que nos hemos referido anteriormente y que es la que ambos autores comparten.

El "Museo" de 1902, en tanto colección unitaria de poemas parnasianos, presenta, como acabamos de ver, una fisonomía particular que lo diferencia de la mayor parte de los restantes poemas de Alma, en los que predomina la influencia simbolista. Consciente de las posibilidades del modelo, que le permite añadir todos los poemas escritos a partir de 1902 en su "modalidad parnasiana," Machado decidirá en 1907 ampliar la sección e independizarla del conjunto del libro, creando así dos secciones diferenciadas, "Alma" y "Museo," a las que añadirá una tercera, articulada en torno a la poesía popular, y a la que titulará genéricamente "Los cantares."

El "Museo" de Alma. Museo. Los cantares, en el que sólo figura un poema no publicado anteriormente, "Fin de siglo," añade a los tres poemas comentados otros cuatro procedentes de Alma, ("Flores,"'Castilla,"'Figulinas," y "Versailles,"); nueve de Caprichos, ("Abel," "Ruth," "Alvar-Fáñez," "Retablo," "Don Carnaval," Madrid Viejo," "Don Miguel de Mañara Vicentelo de Leca," "Un hidalgo" y "Jardín neoclásico,"); uno de La fiesta nacional ("Aquí, en España") e igualmente uno de Tristes y alegres ("El rescate"). En total suman diecinueve poemas distribuidos en cuatro subsecciones: "Oriente" ("Abel," "Ruth" y "Flores"), "Primitivos" ("Castilla," "Alvar-Fáñez," "Retablo," "Don Carnaval," "El rescate" y "Oliveretto de Fermo"), "Siglo de Oro" ("Madrid Viejo," "Felipe IV," "La corte," "Don Miguel de Mañara Vicentelo de Leca" y "Un hidalgo") y finalmente "Figulinas" ("Figulinas," "Jardín neoclásico," "Versailles," "Fin de siglo" y "Aquí, en España").

El "Museo" de 1907 se presenta, por tanto, como una ampliación del de 1902. En ese sentido podemos ver cómo Machado desarrolla al máximo las posibilidades del título, organizando la sección como un verdadero museo, ordenado cronológicamente y dividido en cuatro subsecciones que corresponderían a cuatro imaginarias salas, cada una de ellas con un 
título alusivo a la procedencia geográfica, el período histórico o el estilo representado en ellas. ${ }^{39}$

Por otro lado, la desmembración de la unidad formada por los tres poemas del primitivo "Museo" y la inclusión de cuatro poemas de Alma que habían quedado fuera en 1902 vienen a indicarnos que la concepción de este "Museo" de 1907, como la de un museo real, es básicamente abierta, frente a la estructura cerrada que mostraba en la primera edición. Una prueba de ello es, además, la publicación en 1910, bajo el epígrafe "Museo," de cuatro poemas que serán incluidos después en Apolo. ${ }^{40}$

Las posteriores "remodelaciones" que sufrirá el "Museo" de Machado en Obras completas (1922) Poesías (Opera lyrica perfecta) (1924) y Poesías (Opera omnia lyrica) (1940) se apoyan, por tanto, en esta nueva visión abierta, que el poeta acabará finalmente extendiendo hasta utilizar el título para designar una de las tres voces o maneras en que el autor dividía el conjunto de su obra y que incluía, como ya vimos, a Apolo.

En ese sentido hay que decir que Machado percibía efectivamente una cierta continuidad entre "Museo" y Apolo: además de los mencionados poemas de 1910 y de la lectura de "Felipe IV" en la conferencia "Génesis de un libro," que versaba sobre Apolo, hemos visto ya cómo ambas colecciones de poemas ocupaban el tomo segundo de las Obras completas de 1922. Sin embargo, la concepción de "Museo" y la de Apolo responden a planteamientos diferentes, y ni siquiera se puede decir que "Felipe IV" funcione como nexo entre ambas, ya que, como hemos visto, el motivo del poema no es el cuadro de Velázquez, que no aparece mencionado, sino la figura del rey.

En Apolo la pintura es el objeto explícito de los poemas, mientras que en "Museo" funciona sólo como término de comparación con respecto a la creación poética. En ese sentido debemos señalar que la referencia directa a la pintura que encontramos en Apolo, y en general en los poemas ecfrásticos, no constituye precisamente una muestra de que la sustancia de la poesía pueda equipararse a la de las artes plásticas, sino todo lo contrario. De hecho, toda écfrasis es siempre un intento fallido en el que, frente a la presencia inmanente del objeto artístico, son los valores específicamente literarios del lenguaje poético los que

se reviven la Corte y la aristocracia españolas, con su orgullo, su tristeza y las huellas de su degeneración; constituyen una lección de historia su Felipe IV enfermizo y sus infantas víctimas de una tristeza precoz, con sus actitudes fijas y su aspecto malsano." El origen de esta obra son una serie de conferencias pronunciadas en París entre junio de 1902 y diciembre de 1903. Ignoramos si el autor, profesor de la Escuela del Louvre, pudo haber vertido sus valoraciones en textos anteriores a esa fecha y a los que Machado hubiera podido tener acceso durante su primera estancia en París. Cabe pensar, no obstante, que Reinach se inspirara en el propio Gautier, a quien se debe, como hemos visto, la recuperación de Velázquez en Francia.

39 Machado sigue en este "Museo" de 1907 el modelo de organización histórica de Les Trophées de Heredia, aunque acentuando las connotaciones plásticas de los títulos. Las seis secciones que componen el libro de Heredia son: "La Grèce et la Sicile," "Rome et les barbares," "Le Moyen âge et la Renaissance" "L'Orient et les tropiques," "La nature et le rêve" y "La mer de Bretagne."

40 "Museo. Leonardo da Vinci (La Giocconda). Zurbarán (Entierro de un monje)." La Ilustración Española e Iberoamericana, XLI (1910) 271 y XLVI (1910) 351.

"Museo. Greco (El caballero de la mano en el pecho). Goya (Los fusilamientos de la Moncloa." Los Lunes de El Imparcial, (12-9-1910). 
tienden a aparecer reflejados con mayor nitidez que los supuestamente plásticos. Como señala W. Steiner:

[Ekphrastic poems] express the idea of art's overcoming time without themselves overcoming it. They fail where the visual arts seemingly succeed; what they gain from the topos [of ekphrasis] is an example of what they can merely aspire to do... the outcome is lacking in spatial extension and in the coincidence of aesthetic experience with artifact characteristic of painting. ${ }^{41}$

Por el contrario de los poemas de "Museo" puede decirse que son "como cuadros," pero precisamente en la medida en que no están inspirados en la pintura, sino que, como ésta, tratan directamente, sin medios interpuestos, un aspecto de la realidad, en este caso la historia. Así pues, el principal valor del título de "Museo" es precisamente su condición de metáfora; una metáfora que aun destilando devoción por lo plástico releva a la poesía de cualquier función de transcripción con respecto al arte y la sitúa al mismo nivel.

${ }^{41}$ W. Steiner, The Colors of Rhetoric (Chicago: University of Chicago Press, 1982) 42. 